\title{
Online professional learning for rural teachers of mathematics and science
}

\author{
Sandra Herbert, Coral Campbell, Esther Loong \\ Deakin University
}

\begin{abstract}
Professional learning is crucial for the ongoing development of teachers and the improvement of student outcomes. Professional learning in mathematics and science education has the potential to address concerns about shortages in these areas and their impact on economic growth. However, attendance at face-to-face professional learning is problematic for many teachers located in rural areas. This study explores the utilisation of online professional learning in mathematics and science education by teachers in rural areas, and canvasses teachers' requirements for this form of professional learning. An activity system, using cultural-historical activity theory, is developed for online professional learning for teachers of mathematics and/or science. Qualitative interpretive analysis of transcripts of 14 semi-structured individual interviews with three different groups of people suggests that teachers of mathematics/science require professional learning programs which are not only flexibly delivered but also provide professional learning content that has high utility value. By better understanding how teachers respond to the notion and practice of online professional learning, informed decisions can be made about how best to support teachers and thus build capacity in schools for success in mathematics and science.
\end{abstract}

\section{Introduction}

Provision of scientists and engineers world-wide is in crisis (Barmby, Kind, \& Jones, 2008). In Australia, the Office of the Chief Scientist (2013) reported similar concerns with regard to mathematics and science related fields in general. The Victorian Auditor-General's Report (Government of Victoria, 2012) indicated that the declining university enrolments in science, technology, engineering and mathematics is a major concern with "potential impact on future research, development and innovation capability" (p. vii). Despite a number of strong initiatives to improve science and mathematics education, the progress has not been as expected. Non-metropolitan schools and their students faired much worse in mathematics and science education, with fewer students taking these subjects at higher levels possibly because these schools find it difficult to recruit teachers trained in science and mathematics (Government of Victoria, 2012).

Provision of professional learning (PL) for rural teachers is currently problematic if teachers and presenters are required to travel to a central location. The distances involved, time taken for travel and difficulties with time release, all impact on participation in these sessions. These sessions typically involve teachers' participation in hands-on activities, with access to relevant resources and opportunities to discuss classroom practices (Campbell et al., 2012). Virtual environments can present opportunities for online PL (Duncan-Howell, 2010), but the optimal conditions for PL in mathematics and science education need further exploration. Guskey (2002) emphasised that PL needs to consider participants' learning and reactions; organisational support and change; participants' use of new knowledge and skills; and student learning outcomes. Professional learning in a virtual environment presents particular affordances and challenges. It may have the same elements as Guskey's (2002), but other interactions may also be important, so an activity theory lens has been utilised to view the interactions involved in online PL to better understand it, especially for rural teachers.

This study investigated teachers' perceptions of online professional learning programs, identifying the issues and exploring the effectiveness of this mode of professional learning. The opinions of 10 teachers in rural areas were canvassed regarding their requirements for effective PL in mathematics and science. In addition, four providers of online PL were also interviewed to gain insight into what they considered as being essential for participants. A cultural historical activity theory (CHAT) analysis of the activity system helps to consolidate the findings and provide insight into the way online professional development programs can be designed and implemented. The questions which guided our research are: 
a) What are rural teachers' perceptions of online professional learning, with particular respect to its value in enhancing their understandings?

b) What features of online professional learning would meet the needs of rural teachers?

A review of the literature concerning teacher professional learning provides a context for this study, with reference to frameworks established for professional learning, in particular online teacher PL in mathematics and science teaching. The results highlight teachers' appreciation and concerns with regards to the multiple aspects of online PL for teaching mathematics and science. Finally, the conclusions draw attention to the complexity of providing effective online PL in mathematics and science and the range of expectations of potential participants.

\section{Background}

\section{Professional learning}

The Internet may be used as a tool for instruction, communication and collaboration to deliver professional learning programs to participants who are separated by time and distance. There are a variety of approaches, models and frameworks for its implementation, depending on the learning goals, available technologies, and level of interaction deemed necessary (Vrasidas \& Zembylas, 2004). As e-learning and virtual settings become more widespread, there will be many blends of online PL taking place, with some more successful than others. However, we must first consider the features of professional learning in general to consider how they may relate to the online environment.

PL is considered to be any and all learning undertaken by a teacher in trying to improve their understanding and pedagogy. It can occur in formal ways through professional development programs, informally through peer-to-peer discussions, or independently (Coles, 2012). The language of professional development is still used in some contexts, but tends to imply a more restricted view of teachers' PL through formal external professional development provision. For PL to be effective and to support teacher change in the classroom, it should be ongoing and extended (Coles, 2012) and sensitive to the needs of teachers and schools (Campbell et al, 2007). Opfer and Pedder (2011) emphasised the importance of:

[I]dentifying emergent patterns of interaction within and between levels of activity that would constitute an explanatory theory of teacher learning as a complex system, requir[ing] variable-inclusive (as opposed to control) strategies of research, development, planning, and evaluation. (p. 379)

Hence this study pays attention to interactions in an activity system to explain teacher learning in an online environment.

In the past, professional development often occurred through the medium of one-off workshops, but research has shown this to be quite ineffective in challenging and supporting fundamental change in aspects of teaching practice and beliefs (Borko, 2004; Boyle, While, \& Boyle, 2004). Boyle et al. (2004) advocated concentrating PL on the content which teachers must engage in and be competent to teach. Similarly, Carey, Kleiman, Russell, Venable, and Louie (2008) indicated that:

[E]ffective professional development focuses on the subjects that teachers teach, is aligned with local curriculum standards, deepens teachers' content knowledge and fosters active and inquiry-based forms of learning. (p. 5)

This enables teachers to ground new ideas in their own personal experience - through their social systems, and hence change their practice (Borko, 2004). Loucks-Horsley, Stiles, Mundry, Love, and Hewson (2009) developed a framework to guide the delivery of PL, advocating a cycle of design, implementation, evaluation, reflection and revision, informed by an understanding of the unique features of the context; an awareness and mitigation of possible critical issues effecting success of the program; and a wide range of strategies aligned to goals, context and teacher learning. 
However, access to high quality PL is more difficult for teachers in rural areas than urban teachers (Lyons, Cooksey, Pannizzon, Parnell, \& Pegg, 2006). There is a demand for increasing and improving the provision of online PL for these teachers. In a report to the Department of Education, Science and Training (DEST), Lyons et al. (2006) recommended:

[T]hat education authorities, in partnership with schools and school communities, universities and professional organisations meet the continuing needs of teachers in rural and regional areas through a range of strategies that ensure equitable access to ongoing quality professional learning. (p. xiii)

Like other forms of PL for teachers, online PL is still required to meet the needs of teachers so that it is: embedded, socially and culturally, in each teacher's practice; related to needs of the school and student learning; and contains appropriate content matched to teachers' needs, all of which significantly affect the design of any PL program (Russell, Carey, Kleiman, \& Venable, 2009). An online environment may facilitate PL in ways not available in the face-to-face environment including issues of access regarding time and distance, tailored support to suit an individual's learning style by using a range of multi-media formats, and access to a network of participants from a broad contextual background enabling the development of networking and collaboration amongst participants over time (Carey et al., 2008). Formation of groups, asynchronous chats, and informal discussion spaces are a few suggested strategies to assist in the development of relationships.

When teachers develop open and trusting relationships with community colleagues, they begin to feel less isolated, more willing to work together to tackle student issues, and more open to experiment and to take risks with methods of instruction. (Carey et al., 2008; p.5)

However, they acknowledged that collaborative teacher cultures cannot be created or controlled by external forces, such as a PL facilitator, as it evolves to meet the group's needs. Russell et al. (2009) indicated that some teachers are highly self-motivated needing less support, whilst others benefit from strong interaction in the online environment. However, Carey et al. (2008) raised concerns about the quality of PL on offer and recommended strong guidelines for the development of effective online courses. Like Loucks-Horsley et al. (2009), they advocated a range of strategies aligned with the participants' learning preferences. They found that an extended period of time (10 weeks) with opportunities for quality reading material, increased teacher knowledge, altered pedagogy and changed instructional practice with the outcomes of the online PL were "similar to those that occur in a face-toface environment" (Russell et al., 2009; p. 85). Broadley (2010), in undertaking research into the PL needs of teachers in Western Australia, found that most preferred a blended approach with both online and face-to-face aspects, based on their valuing of the broader learning community with their colleagues. Synchronous discussion, where learners and facilitators are connected online at the same time are seen as beneficial for several reasons (Chen, Chen, \& Tsai, 2009; Dickey, 2003) such as team decision-making, and community building through immediate acknowledgement of each learner as a contributor and responding to issues in real-time.

A recent new direction in online learning including PL for teachers has been the advent of massive open online courses (MOOCs).

A MOOC is an online course with the option of free and open registration, a publicly shared curriculum, and open-ended outcomes. MOOCs integrate social networking, accessible online resources, and are facilitated by leading practitioners in the field of study. (McAuley, Stewart, Siemens, \& Cormier, 2010; p. 10)

Vivian, Falkner, and Falkner (2014) developed a MOOC for teachers by implementing a new computing curriculum which integrated social media for knowledge exchange and resource building. The design principles of the MOOC included meeting teacher needs whilst allowing for flexibility, ad-hoc interactions, support, and the open sharing of resources. They found that participants needed clearer instructions and videos (especially for those not familiar with the platform), and that the compulsory workload for the courses be reduced. 
Online PL can take many forms and vary in effectiveness. Regrettably, studies on the effectiveness of online PL are sparse (Dash, Magidin de Kramer, O’Dwyer, Masters, \& Russell, 2012). This investigation responded to this need to develop a greater understanding of the nature and extent of online professional development in rural areas. It was necessary to use a cultural-historical activity theory lens to explore teachers' requirements for online PL. Since social and cultural elements have pre-existing histories of interaction which influence, shape and alter the nature of the activities, it is important to understand that any current observable activity is related to these origins (Engeström, 1987).

\section{Cultural-historical activity theory (CHAT)}

This study is based on the theoretical framework of cultural-historical activity theory which considers the entire system around an activity such as participation in online PL. It has the potential to capture the complex relationships in an activity system and includes a variety of users, taking into account their environment and motivations, and acknowledges the complexity of real life action. It is useful for understanding how a wide range of factors work together to impact an activity (Engeström, 1987). Engeström and Cole (1997) claimed that activity theory considers "both a collective and an individual perspective" (p. 304). Individual semi-structured interviews have the potential to illuminate individual perspectives whilst a cross-case analysis has potential to focus on a collective perspective thus providing guidance for the development of online PL programs for teachers, particularly in mathematics and science.

Karanasios (2013) provided a framework to employ when considering an activity system. His framework lists a set of useful questions which we used in defining our activity system. In this study, the activity or object of interest is the provision of PL for teachers of mathematics and/or science. The subjects are the providers of PL and the recipients of PL. The tool that mediates this is the online PL that teachers in remote and rural areas may undertake. The activity is taking place because it is difficult for teachers in rural areas to attend face-to-face PL sessions. Typically, PL in mathematics and science are face-to-face sessions with a strong element of discussion, stimulated by hands-on activities (Campbell et al., 2012), so principles of effective face-to-face PL need to be transferred into the online environment. However, it may be that there are particular affordances of the online environment which facilitate different ways of conducting PL. It is anticipated that the PL program would be designed by an individual or team of persons who normally provide online PL and that interested teachers would be the participants, that is, the consumers of the program. The community of the activity system would be educators (education departments, school leaders, teachers, teacher educators), software developers, and the general school community such as the parents who will witness the effect of the teachers' PL on their children's learning. The desired outcome of this activity system is the provision of effective PL in mathematics and science for teachers in rural locations. Figure 1 shows the elements of Engestõm's (1987) activity system, applicable to online professional learning.

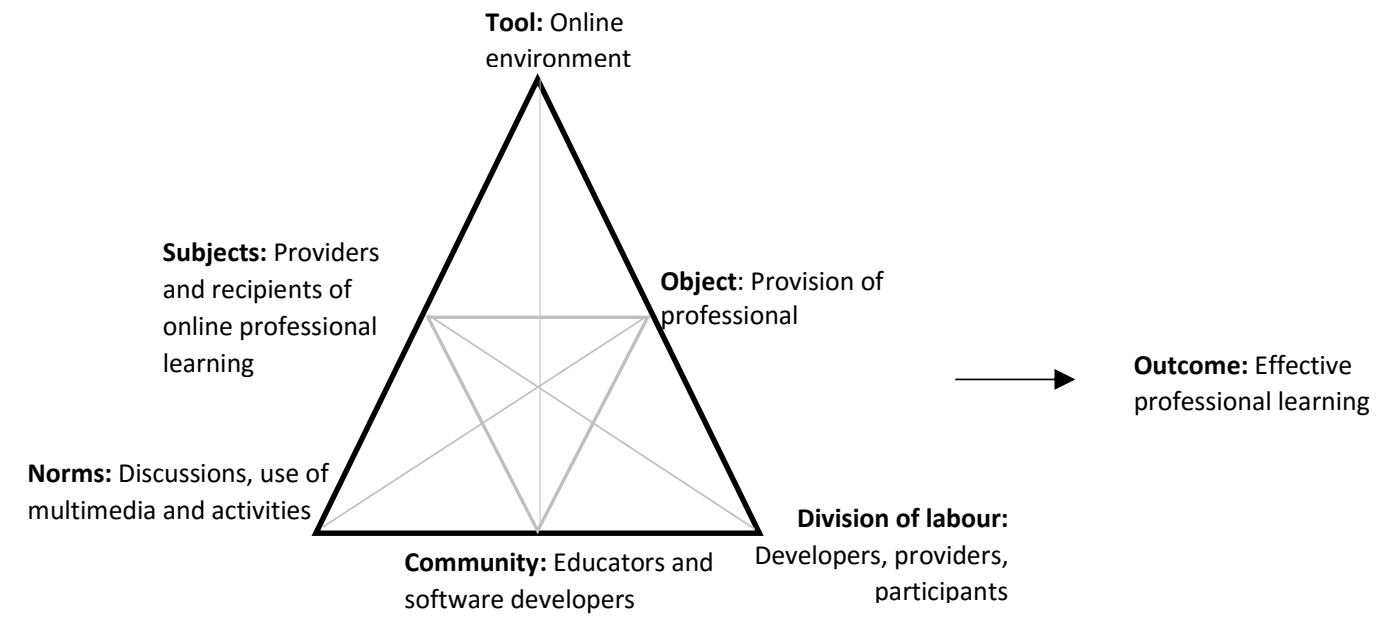

Figure 1. Activity system for online professional learning in mathematics and science based on Engestõm's (1987; p. 78) activity system 


\section{Methodology: Participants, context and methods of the study}

This research used a case study approach (Stake, 2005) informed by a CHAT lens to examine relationships within and between participants. Each participant and their context was considered a case, bounded in time and circumstances (See Tables 1 and 2). Yin (2003) indicates that a case study approach is used when:

- researchers have questions related to how and why of the phenomenon,

- the behaviour or responses of the participants cannot be manipulated,

- contextual conditions are relevant to the study, and

- boundaries between context and research focus are not clear.

An interpretive analysis (Hittleman \& Simon, 2002) is used for a cross case analysis, and leads to theoretically-based implications in response to the research focus. This study brings together the perceptions and opinions of providers, participants and non-participants of online PL. Its purpose is to elucidate the factors which affect the uptake of online professional learning and clarify the extent to which online learning is used by teachers. A subsequent outcome could also be to provide insight into the development of future online programs.

There were 14 participants from rural areas of Victoria: 9 female and 5 male; 2 university staff and 12 teachers, with 8 in a secondary setting and 4 based in a primary school. Four participants were providers of online PL programs and 5 of the teachers were school personnel responsible for arranging or monitoring PL at their school.

An internet search of online professional learning programs was undertaken and this yielded a number of online programs and schools presenting online learning for staff. The schools were approached by the researchers, and participants self-selected into the research study. The online course providers were selected based on the courses they presented, moderated, or have designed. All online providers were contacted by the researchers and all agreed to contribute to the research. Providers of all wholly face to face workshops were excluded from the selection resulting in only providers of wholly or blended online courses being selected for this study. Some of the teacher participants were referred to us by the providers because they had participated in those online professional development courses and these teachers had individually consented to being part of the study.

Table 1

Summary of subjects of the activity system and their involvement in online professional learning

\begin{tabular}{|c|c|c|c|c|c|c|}
\hline Name* & Role & Context & $\begin{array}{l}\text { Duration/ } \\
\text { frequency }\end{array}$ & $\begin{array}{l}\text { Software } \\
\text { Platform }\end{array}$ & Features & $\begin{array}{l}\text { Content } \\
\text { area }\end{array}$ \\
\hline Paige & Provider & Secondary & Weekly & $\begin{array}{l}\text { Blackboard } \\
\text { Collaborate, } \\
\text { webinars, } \\
\text { blogs }\end{array}$ & $\begin{array}{l}\text { Informal, interactive, } \\
\text { sharing of sessions }\end{array}$ & Technology \\
\hline Paul & Provider & Tertiary & $\begin{array}{l}\text { Four 1-hour } \\
\text { sessions }\end{array}$ & $\begin{array}{l}\text { Elluminate } \\
\text { Website }\end{array}$ & On-line static modules & Technology \\
\hline Pam & Provider & Tertiary & Fortnightly & Elluminate & $\begin{array}{l}\text { Real-time presentation } \\
\text { with opportunity for } \\
\text { questions, recorded, part } \\
\text { of graduate certificate }\end{array}$ & Maths unit \\
\hline Phoebe & Provider & Secondary & Weekly & $\begin{array}{l}\text { Webinars, } \\
\text { blogs, } \\
\text { Blackboard } \\
\text { Collaborate }\end{array}$ & $\begin{array}{l}\text { Informal, interactive, } \\
\text { sharing of sessions }\end{array}$ & Technology \\
\hline Lucy & $\begin{array}{l}\text { School } \\
\text { leader }\end{array}$ & Secondary & & $\begin{array}{l}\text { Video } \\
\text { conferencing }\end{array}$ & Forums, consultation & $\begin{array}{l}\text { Australian } \\
\text { curriculum }\end{array}$ \\
\hline Tracy & Teacher & Secondary & Fortnightly & Elluminate & $\begin{array}{l}\text { Real-time presentation } \\
\text { with opportunity for } \\
\text { questions, recorded, part } \\
\text { of graduate certificate }\end{array}$ & Maths \\
\hline
\end{tabular}




\begin{tabular}{|c|c|c|c|c|c|c|}
\hline Tim & Teacher & Secondary & As required & Web browser & Self-initiated web-based & $\begin{array}{l}\text { How to's for } \\
\text { software }\end{array}$ \\
\hline Len & $\begin{array}{l}\text { School } \\
\text { leader }\end{array}$ & Secondary & $\begin{array}{l}\text { Whenever } \\
\text { possible }\end{array}$ & Web browser & $\begin{array}{l}\text { Eight online modules with } \\
\text { guided reading, then } \\
\text { practice component such } \\
\text { as analysing school data. } \\
\text { An area where you logged } \\
\text { into, where we could } \\
\text { access all the material and } \\
\text { submit assignments. }\end{array}$ & $\begin{array}{l}\text { Peer learning } \\
\text { teams for } \\
\text { numeracy }\end{array}$ \\
\hline
\end{tabular}

* Pseudonyms

To gain further insight into online professional learning, school personnel and teachers who had not participated in any online PL program were also invited to participate (Table 2). They were considered part of the community (within the activity system) from which the participants are drawn. The selection of this sample was intended to exemplify a broad diversity of opinions regarding the suitability of the online environment for PL in mathematics and/or science. In addition, it was difficult to find teachers who had experienced online PL specifically in mathematics or science. Hence, teachers who had participated in any online professional learning were also invited to participate.

Table 2

Participants in the study who have not engaged in any online professional learning

\begin{tabular}{lll}
\hline Pseudonym & Role & Context \\
\hline Larry & School leader & Primary \\
Linda & School leader & Primary \\
Lynette & School leader & Primary \\
Terry & Teacher & Primary \\
Tess & Teacher & Secondary \\
Tegan & Teacher & Secondary \\
\hline
\end{tabular}

Interviews were semi-structured and probed for both the context of learning for the participant and the participant's perceptions and experiences of online learning. As the participant categories varied from provider to participant (primary and secondary), questions were generated through the discussions themselves, although structured questions were used as stimuli when needed, for example school leaders were asked, "Please describe your role and your input into the professional learning of teachers" (See Appendix A). Each participant was interviewed by a member of the research team for approximately 30 minutes either face-to-face (where possible) or via telephone and audio recorded. The transcriptions provided the data for the analysis. It was first categorised according to the emerging themes of the interview responses and then coded and analysed inductively for more fine-grained themes and subthemes.

\section{Results}

Data from the participants were analysed and categorised as seen in the following sections. This analysis contributed to the analysis of the activity system and the development of the activity model (Figure 2).

\section{Reporting on effectiveness}

Overall, most teachers felt that online professional learning was effective for them as it allowed them greater flexibility in how they used their time. However, there were also some negative comments about the productive use of time in undertaking tasks.

[T]he teachers really loved it because it was something that they could do in their own home or in their schools so at the end of the day they could go home and put their headphones on. It meant that they could communicate with people that were on the other side of the state [and] it was taped so then if they did miss it or the ICT component fell down in their school or they couldn't get into the Net connection. (Pam - provider) 
With the limited ones we've been involved with, I don't think it's really valuing people's time. It's nearly like, experimental stuff - "We'll give them these sheets and they can play around with these sheets while we talk about the sheets." (Len - user)

Sometimes engagement in online PL is a requirement of a course or employment. The outcomes of mandated on line learning haven't been investigated in this research, but are noted as possibly a concern or coercion.

[I]t was basically a third of a masters, so because they wanted to pass the course, the incentive was to go on-line. (Pam - provider)

[N]ew casual academic staff, unless they have an exemption, are expected to complete within their first trimester at [the university]. (Paul - provider)

\section{Program design}

There did not seem to be much thought given to the efficient design of a program and as indicated in the discussion on the division of labour; little collaboration occurred between a provider and participants to ensure that the program was tailored to participants' needs.

I just had done a similar presentation before, as a face-to-face lecture so I just thought about, well, how will I adapt it? I think that they communicated, often sent emails to each other through the course too but I'm not sure whether they actually did. I don't think they did a Skype without me. (Pam - provider)

You submitted your tasks on-line - it was just an area where you logged into, where we could access all the material and assignments - there was the opportunity for blogs and discussion to take place - that side of it was pretty well under utilised. There's [sic] six face-to-face workshops, and there's a number of the Webinars. I think we're only just starting to dip our toes in the water with things like that. A number of schools in our area have now got the teleconferencing capabilities, so we're starting to tap into that - we use a phone line through to the TV and set up with a camera. (Len - user)

Participants' comments reflected the narrow approach taken in many online professional learning situations but acknowledged that there was room for substantial growth and change around new technologies which could be further incorporated into the online learning environment.

\section{Challenges}

For providers, the challenges to providing online PL are many. For some providers, it required a change in presentation style and a need to be aware of practical considerations. These include for example, confidently interacting with the PL material as well as ensuring engagement and interaction.

Well I found it tricky trying to read the script on the side as well as concentrate on the PowerPoint and talk, and watch the people as well - so whether you just rehearsed more so that you were more confident with what you were saying, so then you could focus more on the participants. So I took that PowerPoint and then I actually put some links in it to the Internet, and I didn't realise that you couldn't navigate the Internet like you do normally, so that was an error. (Pam - provider)

From the participants' point of view, one of the single biggest challenges was the technical issue related to poor internet connectivity.

[B] ut the negative aspect was the issue of the Internet. Sometimes couldn't hear the words the issue of logging in, those types of technical issues, which do put you off. (Tracy - user) 
This challenge is a crucial element of online professional learning - without an efficient internet connection, the program suffers, regardless of content or intent.

\section{Impetus for online professional learning}

Participants were aware of the limitations of their geographical situations and how that affected their professional learning opportunities. They bemoaned the fact that they didn't have access to quality professional learning through local environments.

I have been quite interested to do some aspects of Year 11 and 12 mathematics, but I haven't been able to find any educational provider in Australia - apart from just one which is UniLand in Queensland I think. (Tracy - user)

There's a lot of PL in Melbourne, certainly for maths and I'm sure in the other subjects that start at half past three and finish at half past five, or start at four and finish at six, well we clearly can't go to any of those, so if you could link in to that sort of thing it' $d$ be great. (Tegan - non-user)

Yes [initially face-to-face], and we've been having facilitators working with our small groups who give people that face-to-face contact. Basically the project got too big for it to operate like that, so it went on-line, and it became a very onerous task. (Len - user)

The use of an online environment to enable a greater number of participants in a professional learning situation was raised by one participant who saw potential. Unfortunately, the greater the number of participants, the greater the workload, which brought forward other considerations.

\section{Schools' approaches to professional learning}

This study found that rural schools tend to have an economic approach to how PL is to be carried out. It is deemed better value if more staff can benefit from a single interaction rather than have multiple staff going out for the same program. As such, online programs that allow multiple staff to be involved at any one time are considered advantageous. The following comments reflect this:

[We prefer] in-house professional learning from a whole school perspective or a faculty perspective, and then sometimes have others visit us. I encourage people to visit us, being somewhat remote, we get a lot more for our dollar if someone comes to us, rather than paying for accommodation and travel and transport and all of those things that would take people to Melbourne. (Lucy - user)

Because of time, travel, which is expense and time - we're certainly trying to get more PL here at school, because in the end it saves time and money, if you've got one person here and you can get several people pulled out to do that. (Tegan- non user)

Other responses however, indicated the value placed on travelling to a venue, where useful discussion can take place before and after the session during the travel time.

Would I pay the same, for the same thing on-line? Probably not, because you get the enjoyment out of actually going to Melbourne [and] that amazing amounts of professional discussions that happens in cars and on the trains from the teachers, and you have reflected for 4 hours on the PD [professional development] and it sinks in. (Terry - non user)

\section{Desirable features of online professional learning}

Several aspects of online professional learning were regarded as needed or desirable by participants. These included; the optimum number of participants, the relevance of the material to classroom teaching and learning, the modelling of strategies within the PL, the aesthetics (visual appeal) of a site and its interactivity, readily accessible resources, availability, and finally, cost. The effectiveness and value of PL 
seem to be linked to the number of people who are actively involved at one time in the program. It would seem that for an online program to have the synergy and interactivity that sustains engagement, the number of active participants is crucial. This can be seen in the following comments.

Professional learning is very effective when there are a number of people who are investigating or learning in the same area. (Lucy - user)

[T] he more participants you have, the more interactive it can become. (Paige - provider)

A key feature of these responses relates to the idea of active participants, almost as much as the number of participants. Learning was more effective through the interactivity of participants where there is support for one another.

Participants regarded authenticity and relevance as important aspects of online programs instead of theory. PL which had direct classroom application and relevance to teachers' pedagogy was valued. Participants preferred to be given time to conduct classroom trials of the ideas provided by a PL facilitator.

Giving people the opportunity to have some ideas put to them - go away, have a go at implementation, and then have the opportunity to feed-back in those on-line forums success or otherwise - strengths, weaknesses, whatever they may have been - just to continue that development. (Len - user)

One other feature reported as desirable is the modelling of how best to use a certain piece of technology or resource in the classroom from expert others. The opportunity to actually see how some strategy or resource can be used effectively was considered a good use of online PL time.

[A] PD on how best use of Manga High or Khan Academy to improve your students' outcomes, that would be gold. There are so many of them, when we're getting on it for the first time, it's "Whoa what is this? This looks great, how can I best utilise it?" and we fiddle our way through it and fumble, and we get there in the end, but we've wasted so much time. So anything along those lines where you can get feedback directly from a presenter or showing you how to best use it. (Tim - user)

[R]eal situations - videos would be fabulous because the bottom line in our educational leadership and in any teacher's PD is - yeah okay you've given me all this theory - but what does it look like? How do I implement that into my classroom? (Lynette - non-user)

I would like to go to PD's where the person delivering the PD has tried things out before and can give me fairly explicit information on how to use it. If my school had provided me with IPads, I would like someone to show me right down to the finest detail how to use the iPad, how to organise my workflow and how to try out some of the best really good applications that link to the curriculum. (Paige - provider)

Online sites which used easy forms of communication and were visually engaging were appreciated by the participants and regarded as displaying desirable features which lend themselves to learning.

I think you need good visuals to be able to really see. Because with the CAS, there is software so that it can be projected up on the board, so you can see the CAS at one side which highlights which buttons he's pressing, and you've got another part of the screen where you can see what's coming up. So you need to be able to see, really clearly as if you were sitting in the classroom and then you'd have to hear what was going on as well. You need to have easy interaction - that if you've got a question you can ask that question, so it's got to be a two-way communication. (Tegan - non-user)

I think real time would be [good]. It need not be for the whole thing. A proportion of the session could be done at your leisure, and then there could be an allocated 1 hour of Skype time where people could come together and will be addressing things. (Tess - non-user) 
The continuing access to resources previously made available in both on and offline mode seem to be considered an important component of effective online learning provision. The ability to be able to come back to resources at a later date means that the material and PL learning have longer, ongoing effects.

[A]ccess to activities and clips that you can still go back to after it's done. You should be able to access off-line content after it's done which has previously been accessible on-line. (Terry - non-user)

The availability of a program was mentioned as an important feature - when, where and how teachers could access the online PL. As the cost of the PL was also a determining factor in its uptake of a PL program, one participant commented on the possibility of a trial or sampling. This user of online PL expressed views regarding the availability and cost of PL.

I was hoping because maths and science teachers are so much in demand the department would like to train where people are keen to move to secondary area, and provide some scholarships and there's nothing available. Like if you're doing full-time work and then you want to do extra science and mathematics, then there's only one university that I have find so far that can do it through the Certificate of Education. The full fee is $\$ 2000$ per unit, and Commonwealth supported fee is $\$ 1000$. (Tracy - user)

The following non-user of online PL felt that value for money was an important factor and some way to make a judgement on the quality of the program before committing, was how he would view the potential of PL. Perhaps unrealistically, he expressed the view that some samples of the program be made available as a trial so that the prospective participant have a feel for the program and what is has to offer.

If there's a price, justify the price. I look at a professional development thing, and say it's $\$ 670$, it doesn't say why. Like I don't know if I want to go and pay $\$ 670$ for something I might like. So that's why the trial thing should be there - a clip of what this might be about - the stuff it's got to cover before you actually go. (Terry - non-user)

\section{Activity system for online professional learning}

The activity system shown in Figure 1 provides structure for the reporting of the results and relates to those participants who have been involved in professional learning using an online environment. The ultimate outcome in this activity system is the provision of effective PL in mathematics and science for teachers in rural areas. To understand and explain how this can be achieved requires investigation into the different key elements that are at play. The various elements (object, subject, tools, norms, community, division of labour) which lead to the outcome of the provision of effective online professional learning, are described below. The object of this activity system is the provision of PL for teachers of mathematics and/or science in rural areas. However, the actual goal or aspirations of providers of the online PL is one of improvement amongst teachers; possibly an enhanced more meaningful teaching experience as well as more meaningful learning among students.

$[\mathrm{H}]$ oping that working with teachers naturally leads to some kind of improvement in the teaching/learning experience. (Paul - provider)

Within this system, the subjects are the providers and recipients of online PL. Previously in Table 1, the subjects were listed, their involvement highlighted, and their context described. This table also highlights the tools through which the PL programs were mediated. The use of several different tools was reported by the subjects (see Table 1). The four providers used the same platform, namely Blackboard Collaborate (formerly known as Elluminate), with supplementary use of webinars and blogs by some via a web browser. Whilst we recognise that there may be limitations (in teacher learning) in terms of the restricted software platforms reported here, this was outside our control and reflected the professional choices of the providers.

[W]e used a program called Elluminate where we could use our PowerPoint presentations in that program, as you spoke to it, participants could just type in little comments - they 
could speak. It was recorded so then they could log on and play it back. With Skype especially, maybe some of the country schools with slower dial-up or whatever they had, it's a bit tricky. We didn't do the video because you can't, you'd blow up your computer, so it's only voice. So really, Skype was just a seven way phone call. (Pam - provider)

Recipients of the programs used a variety of tools such as paper based materials, online platforms such as video conferencing systems, and learning management systems.

[S]ome sort of professional reading at the start, followed by some sort of practice component, then the submission of basically an assignment with each of the modules. (Len - user)

[S]he's working with two staff members on implementing one-to-one ICT Devices in Year 9, and she's a consultant for us [via] video conferencing. (Lucy - user)

There was nothing unique or unusual about the tools used within the activity system, nor could we suggest from the data provided, that the tools contributed significantly to the system's outcome. Online discussions both synchronous and asynchronous, verbal as well as written seem to be the norm in this activity system and is evident in five transcripts. However, there was no mention about the rules or etiquette expected in these discussions (Shea, 1994). Little creative use of multimedia was reported by the participants other than presentation software (e.g., PowerPoint) facilitating online delivery of content. There was no evidence of higher order thinking skills being required through creative design of activities. This finding links with the use of limited software platforms and possibly a narrowly focussed professional learning outcome.

When thinking of the community of this study, we have included providers of online PL, school leaders and teachers in rural areas, with some evidence of support from education departments through publicity and facilitation of online PL events. Table 2 provided information about teachers who were interviewed, but were not users of online PL. It was interesting to note that none of the participants from primary school settings had engaged in online PL. Various factors inhibiting their engagement in online PL were expressed.

I think the restrictions are, you're doing it alone, you lack motivation, you don't fit it in, you don't make the time because you're not motivated and it's boring if you're just reading something. (Tegan - non-user)

However, they did describe scenarios where they would consider engaging in online PL.

[I]f you were doing it [online PL ] in a school with people it might be more motivating and if the principal was happy to set aside time - well there you go - there's your collegiate group - as a professional learning team. (Lynette - non-user)

So if it's interactive and you're getting that collegiate feedback, and you're seeing what it looks like in a classroom situation where you're going away and coming back and talking about it, it's going to give you much more motivation isn't it. (Tegan - non-user)

In considering how each group contributed to the division of labour, providers and recipients all reported that programs were designed either by the provider or an external entity, who mandated the content of the program. In some cases, input from recipients was sought at the completion of the program and this feedback provided an opportunity for the further development of future iterations of the program.

I did one presentation about how I use technology to tutor students in Maths and Science, so I showed the apps I use, and the programs I use, and the Wiki we use. (Paige - provider).

There was no evidence to suggest that the providers and recipients collaborated to develop an online program responsive to participants needs. 
The activity model of online professional learning provides a framework for us to interrogate what factors within the key elements of the system plays a role in determining how effective professional learning can occur amongst teachers (see Figure 2). Comments from different participants shed light on each of the elements in the system thus enabling the model to be further developed.

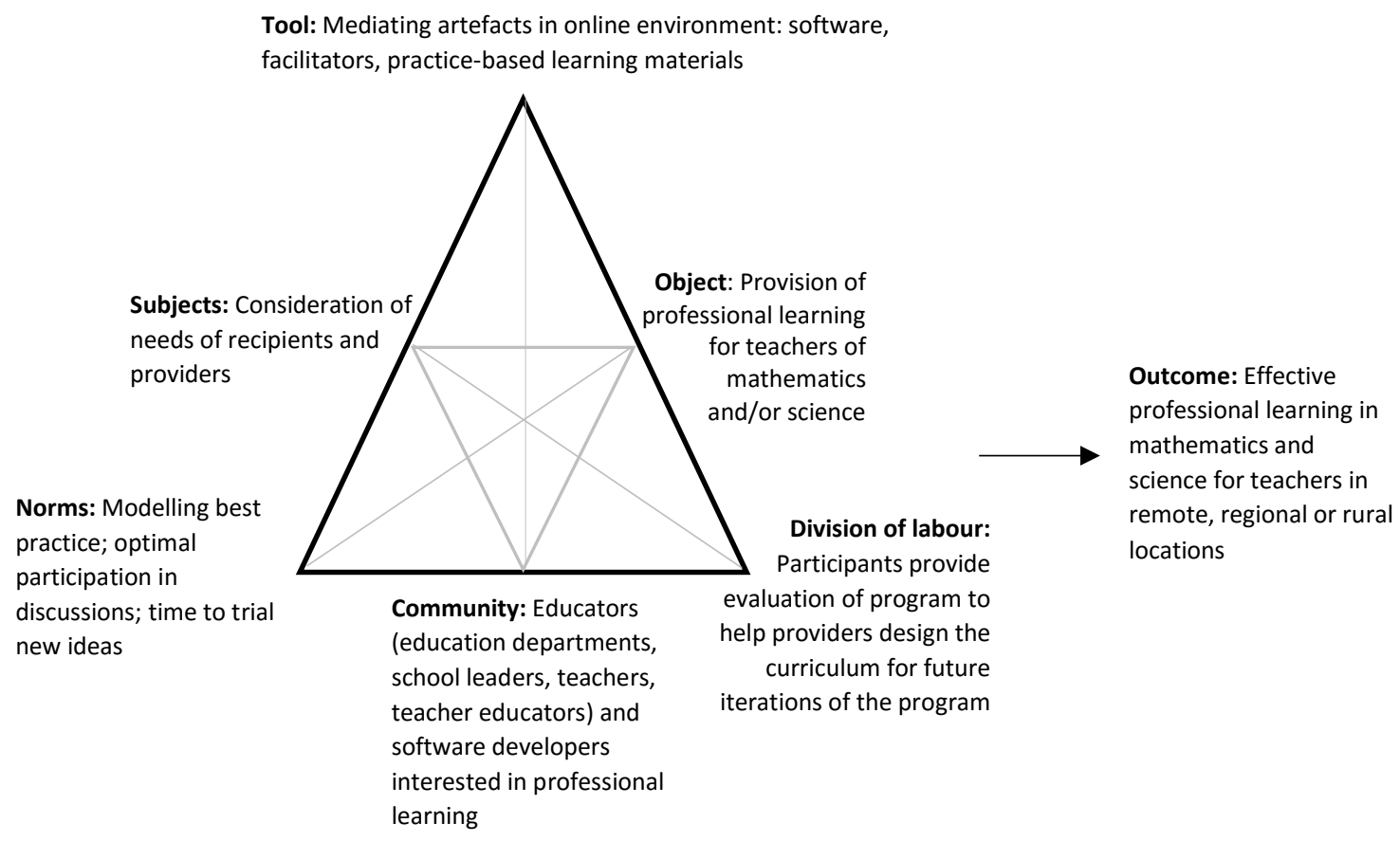

Figure 2. An explanatory activity model for online professional learning

\section{Discussion and conclusion}

This investigation found that the teachers expressed some of the same ideas about the effective provision of online PL as Guskey (2002), such as the importance of support structures within the school, the time and opportunity to translate new ideas into practice, the need for relevant and context specific training, and the opportunity for synchronous communications. In addition, other interactions including the implementation of strategies that could enhance active participation from as many members as possible, as well as continued access to resources, appear to be important to participants. It might be that these will form the norms that govern effective online PL. While the norm in most face-to-face professional learning is the modelling and the discussions, similarly the norms in online systems should model best practices within a topic of work and discussions should be organised in such a way that the synergy of the group will enable fruitful and meaningful learning among participants. Norms such as setting an optimal number of participants and productive negotiations of discussions and discussion spaces holds potential for engendering learning.

On the surface it appears that the mediating artefact or tool is simply the online environment. However what contributes to the online environment and what factors determine its efficacy? This study found that there are three factors, namely; (a) the vehicle for delivery, (b) the human resources, and (c) the learning material. The vehicle for delivery is a function of the software's capabilities, the design of the learning environment, the available connectivity, the aesthetic appeal and ease of use of the software. The second factor that mediates learning is the human factor; facilitators who are competent, confident and provide occasional real time, virtual face-to-face interaction. Both participants and providers were mindful of this factor. Learning material, which is the third factor, should be easily accessible online and have greater utility value, that is, be more practice-based than theory laden.

The division of labour in the activity model refers to who has the say. For learning to be effective, participants ought to have a say in what they want to learn, how they learn and when they learn. Hence 
evaluation of a program by participants is essential for the further improvement of the program. Designers and providers of PL could benefit from teachers' input in the design of the program.

Findings (refer Table 1) show that the content area of technology was the most frequent area reported by the participants. Perhaps this is not surprising as some level of competence in technology is required to engage in online PL and so participants may demonstrate an interest in this area. This, along with comments from non-participants, suggests that to encourage engagement in a broader range of online PL experiences and a broader range of participants, the technical issues need to be minimised. One way this could be done is by providing carefully constructed step-by-step instructions, well in advance of the intended commencement of the program with an initial session wholly devoted to access issues.

Schools' approaches to the provision of PL in mathematics and science were varied, with some schools expressing the cost effectiveness of bringing providers of PL to their school, rather than the costly exercise of sending teachers to major centres to attend sessions. However, such approaches do not take into account the body of research recommending that PL is most effective when spread overtime (Carey et al., 2008). Online delivery has the potential to do this in a cost effective manner, but the design of such programs depends on school leadership providing a dedicated time for relevant staff to participate as a group so a sense of collegiality is promoted and motivation levels remain high. Engeström and Cole (1997) explained that in activity systems, equilibrium is an exception whereas "tensions, disturbances, and local innovations are the rule and the engine of change" (p. 8). How school systems creatively circumvent these dilemmas may well bring about the desired change necessary for sustained effective professional learning among teachers.

This investigation revealed several key requirements of online PL expressed by the participants of this study. Together teachers' and providers' views revealed insights into the implementation of online PL programs and the challenges faced. The primary result of the investigation is an activity model (Figure 2) reflecting our participants' perceptions of the critical components of a successful online PL program for teachers. The activity model developed from the data collected provides a way of assessing whether online PL programs in teaching mathematics and science meet the needs of potential participants. It provides insights into the way such PL programs could be designed to maximise the change in teachers' practice in teaching mathematics and science. It offers designers of PL programs knowledge of teachers' key requirements to embed in future online PL settings. In addition, this framework can be used in a larger-scale study to determine the prevalence of these requirements to gain an understanding of the needs of teachers undertaking online PL in mathematics and science. It may serve to guide the professional learning of mathematics and science teachers within the online environment and may help to ensure that rural teachers are provided with the same PL opportunities as their metropolitan counterparts.

Although it was intended to capture the views of a wide diversity of rural participants regarding online PL in mathematics and/or science, it was found that few teachers had participated in this mode of PL and only one of these in the particular curriculum area of mathematics. Nevertheless, the views of those who were interviewed do illuminate teachers' requirements for their participation in online PL and highlight inhibiting factors to their participation. These findings may also have been limited by the participants' lack of appropriate opportunities to engage in online PL, possibility due to lack of information about its availability. The fact that only four providers were found, is indicative of a possible issue in professional learning provision as well. Online publicity of these programs tends to attract the converted and does little to open up the possibilities for rural teachers. In spite of these limitations, this study makes available thought provoking reflections of teachers about their requirements for online PL in mathematics and science.

\section{References}

Barmby, P., Kind, P., \& Jones, K. (2008). Examining changing attitudes in secondary school science, International Journal of Science Education, 30(8), 1075-1093. doi:10.1080/09500690701344966

Borko, H. (2004). Professional development and teacher learning: Mapping the terrain author(s). Educational Researcher, 33(8), 3-15. doi:10.3102/0013189X033008003

Boyle, B., While, D., \& Boyle, T. (2004). A longitudinal study of teacher change: What makes professional development effective? The Curriculum Journal, 15(1), 1-27. doi: $10.1080 / 1026716032000189471$ 
Broadley, T. (2010). Digital revolution of digital divide: Will rural teachers get a piece of the professional development pie? Education in Rural Australia. 20(2), 63-76. Retrieved from http://espace.library.curtin.edu.au/R?func=dbin-jump-full\&local base=gen01era02\&object $\mathrm{id}=167366$

Campbell, C., Chittleborough, G., Hubber, P., Tytler, R., Barty, K., \& Stacey, E. (2007). Using ICT to support literacy and numeracy in rural schools: Evaluation report of a project of the Association of Independent Schools of Victoria. Retrieved from http://www.ais.vic.edu.au/schools/research/index.htm

Campbell, C., Chittleborough, G., Hubber, P., Tytler, R., Jobling, W., Cripps-Clarke, J., ... \& Herbert, S. (2012). Primary science specialist learning program - Evaluation of delivery, DEECD (Department of Education and Early Childhood Development), State of Victoria, Melbourne, Victoria.

Carey, R., Kleiman, G., Russell, M., Venable, J. D., \& Louie, J., (2008). Online courses for math teachers: Comparing self-paced and facilitated cohort approaches. Journal of Technology, Learning, and Assessment, 7(3), 1-33. Retrieved from http://www.jtla.org

Chen, Y., Chen, N-S., \& Tsai, C-C. (2009). The use of online synchronous discussion for web-based professional development for teachers, Computers \& Education, 53(4), 1155-1166.

Coles, P. (2012). Linking effective professional learning with effective teaching practice. Education Services Australia. Retrieved from http://www.aitsl.edu.au/docs/default-source/default-documentlibrary/linking_effective professional learning with_effective teaching practice - cole

Dash, S., Magidin de Kramer R., O’Dwyer L. M., Masters J., \& Russell M. (2012). Impact of online professional development on teacher quality and student achievement in fifth grade mathematics, Journal of Research of Technology in Education, 45(1), 1-26. doi:10.1080/15391523.2012.10782595

Dickey, M. D. (2003). Teaching in 3D: Pedagogical affordances and constraints of 3D virtual worlds for synchronous distance learning. Distance education, 24(1), 105-121. doi:10.1080/01587910303047

Duncan-Howell, J. (2010). Teachers making connections: Online communities as a source of professional learning. British Journal of Educational Technology, 41(2), 324-340. doi:10.1111/j.1467$\underline{8535.2009 .00953 . \mathrm{X}}$

Engeström, Y. (1987). Learning by expanding: An activity-theoretical approach to developmental research. Helsinki: Orienta-Konsultit. doi:10.1017/CBO9781139814744

Engeström, Y., \& Cole, M. (1997). Situated cognition in search of an agenda. In D. Kirshner, \& J. A. Whitson (Eds.), Social, semiotic, and psychological perspectives (pp. 301-309). Marwah, NJ: Lawrence Erlbaum Associates.

Government of Victoria. (2012). Victorian Auditor-General's report. Retrieved from http://www.audit.vic.gov.au/reports and publications/reports by year-2012-13.aspx

Guskey, T. (2002). Professional development and teacher change. Teachers and Teaching, 8(3), 381-391. doi: $10.1080 / 135406002100000512$

Hittleman, D. R., \& Simon, A. J. (2002). Interpreting educational research. An introduction for consumers of education. Columbus, $\mathrm{OH}$ : Pearson Education.

Karanasios, S. (2014). Framing ICT4D research using activity theory: A match between the ICT4D field and theory? Information Technologies \& International Development, 10(2), 1-17.

Loucks-Horsley, S., Stiles, K. E., Mundry, M. S. E., Love, N. B., \& Hewson, P. W. (2009). Designing professional development for teachers of science and mathematics. Thousand Oaks, CA: Corwin Press.

Lyons, T., Cooksey, R., Panizzon, D., Parnell, A., \& Pegg, J. (2006). Science, ICT and mathematics education in rural and regional Australia: The SiMERR national survey. University of New England, National Centre of Science, ICT and Mathematics for Rural and Regional Australia.

Office of the Chief Scientist. (2013). The Chief Scientist. Retrieved from http://www.chiefscientist.gov.au/about/the-chief-scientist/

Opfer, V. D., \& Pedder, D. (2011). Conceptualizing teacher professional learning. Review of Educational Research, 81(3), 376-407. doi:10.3102/0034654311413609

McAulay, A., Stewart, B., Siemens, G. \& Cormier, D. (2010). The MOOC model for digital practice. University of Prince Edward Island, Canada. Retrieved from http://www.elearnspace.org/Articles/MOOC_Final.pdf

Russell, M., Carey, R., Kleiman, G., \& Venable, J. D. (2009). Face-to-face and online professional development for mathematics teachers: A comparative study. Journal of Asynchronous Learning Networks, 13(2), 71-87.

Shea, V. (1994). Netiquette. Vancouver, Canada: Albion Books.

Stake, R. (2005). Qualitative case studies. In N. K. Denzin, \& Y. S. Lincoln (Eds.), The Sage handbook of 
qualitative research (3rd ed., pp. 443-466). Thousands Oaks, CA: Sage Publications.

Vivian, R., Falkner, K., \& Falkner, N. (2014). Addressing the challenges of a new digital technologies curriculum: MOOCs as a scalable solution for teacher professional development. Research in Learning Technology, 22. doi:10.3402/rlt.v22.24691

Vrasidas, C., \& Zembylas, M. (2004). Online professional development: Lessons from the field. Education + Training, 46(6/7), 326-334. doi:10.1108/00400910410555231

Yin, R. K. (2003). Case study research: Design and methods (3rd ed.). Thousand Oaks, CA: Sage.

Corresponding author: Sandra Herbert, sandra.herbert@deakin.edu.au

Australasian Journal of Educational Technology (c) 2016.

Please cite as: Herbert, S., Campbell, C., \& Loong, E. (2016). Online professional learning for rural teachers of mathematics and science. Australasian Journal of Educational Technology, 32(2), 99-114. 


\section{Appendix A}

\section{Interview questions probing perceptions of online professional learning}

\begin{tabular}{|c|c|}
\hline $\begin{array}{l}\text { Principals/PL Co-ordinator } \\
\text { Please describe your role and your input into } \\
\text { the professional learning of teachers (in maths } \\
\text { and science)? } \\
\text { Are there any professional development } \\
\text { sessions being conducted or held in your } \\
\text { school? How many teachers involved? Since } \\
\text { when? What do they do? What is involved for } \\
\text { the teachers? } \\
\text { What is your opinion re- effectiveness of PD } \\
\text { Are you encouraging staff to do it? Why/ why } \\
\text { not } \\
\text { Nature- wholly online or mixed mode delivery? }\end{array}$ & $\begin{array}{l}\text { Participating Teachers } \\
\text { Have you done any PD on-line? Please } \\
\text { describe it. } \\
\text { What would you like an online PD to look } \\
\text { like? } \\
\text { How did you find out about the provider? } \\
\text { What did you like /not like about the online } \\
\text { PD? } \\
\text { Has the PD helped you to improve skills } \\
\text { /knowledge? }\end{array}$ \\
\hline $\begin{array}{l}\text { Providers } \\
\text { Please describe the online professional learning } \\
\text { in mathematics/science provided by your } \\
\text { organisation. } \\
\text { Can you please explain in greater detail what } \\
\text { you have done and why? } \\
\text { Tell me about the PD you offer } \\
\text { What is the distribution of participants - } \\
\text { Primary /secondary and Math/science? } \\
\text { Basis for designing a particular PD? } \\
\text { Infrastructure -technology? } \\
\text { Content? Evaluation of effectiveness? } \\
\text { How is feedback treated? } \\
\text { How many schools in one PD? How many } \\
\text { teachers involved? How long has the PD been } \\
\text { offered? What is involved for the teachers? } \\
\text { When is PD available? How do you encourage } \\
\text { or recruit schools? What is the marketing } \\
\text { strategy/publicity? } \\
\text { Nature- wholly online or mixed mode delivery? }\end{array}$ & $\begin{array}{l}\text { Non-Participating Teachers } \\
\text { Have you participated in any PD at all in } \\
\text { maths and science? } \\
\text { What have you done so far? } \\
\text { Would you do online PD? } \\
\text { What do you think would be the barriers or } \\
\text { benefits? } \\
\text { What would the online PD have to be like for } \\
\text { you to use it? }\end{array}$ \\
\hline
\end{tabular}

